\title{
The impact of genital psoriasis on quality of life: a systematic review
}

This article was published in the following Dove Press journal:

Psoriasis: Targets and Therapy

\section{Eric J Yang ${ }^{1,2, *}$ \\ Kristen M Beck ${ }^{1, *}$ \\ Isabelle M Sanchez ${ }^{1,3}$ \\ John Koo' \\ Wilson Liao'}

'Department of Dermatology, University of California San Francisco, San Francisco, CA, USA $;{ }^{2}$ Chicago Medical School, Rosalind Franklin University of Medicine and Science, North Chicago, IL, USA; ${ }^{3}$ University of Illinois at Chicago College of Medicine, Chicago, IL, USA

*These authors contributed equally to this work
Correspondence: Eric J Yang

Department of Dermatology, University

of California San Francisco, 515 Spruce

Street, San Francisco, CA, USA

$\mathrm{Tel}+\mathrm{I} 8583225414$

Fax + I 4155024126

Email ericjyang@outlook.com

\begin{abstract}
Psoriasis is a chronic immune-mediated inflammatory disease with significant medical and psychological comorbidities. In addition to having increased cardiovascular risk and mortality, psoriasis patients are more likely to be depressed, anxious, and endorse suicidal ideation than the general population. These patients often have low self-esteem and feel stigmatized due to their skin disease, which can prevent them from pursuing relationships, dating, and attending social activities. Up to $63 \%$ of adult psoriasis patients experience psoriatic lesions on their genital area during their lifetime, but often do not discuss these issues with their physicians due to embarrassment, stigmatization, or shyness about this sensitive location. However, psoriasis in sensitive areas, such as the genitals, may result in quality of life impairment greater than that of patients with psoriasis elsewhere on their body, particularly in respect to romantic relationships, intimacy, and sexual function. This article evaluates the current literature regarding the impact of genital psoriasis on the quality of life of affected patients.
\end{abstract}

Keywords: genital psoriasis, quality of life, sexual function, sexual distress, impact

\section{Introduction}

Psoriasis vulgaris is a chronic immune-mediated systemic inflammatory disease affecting $2 \%-3 \%$ of the US population. ${ }^{1,2}$ Psoriasis is often associated with scaly, well-demarcated papules and plaques that may appear anywhere on the body. ${ }^{3} \mathrm{Up}$ to $63 \%$ of adult psoriasis patients experience psoriatic lesions in their genital area at least once during their lifetime, ${ }^{4}$ but these localized lesions are often overlooked. Physicians often do not specifically ask about or examine these areas, ${ }^{5}$ and patients may be reluctant to bring up such sensitive topics when not prompted. Thus, almost half of all patients with genital lesions do not discuss their symptoms with their physician ${ }^{6-8}$ and may be undertreated. ${ }^{7}$

Although thought to be "just" a skin disease long ago, psoriasis is now wellcharacterized to have various medical and psychological comorbidities. Patients with psoriasis have increased cardiovascular risk and mortality ${ }^{9,10}$ and are more likely to be depressed, anxious, and endorse suicidal ideation than the general population. ${ }^{1-14}$ Affected patients often feel stigmatized, have low self-esteem, are embarrassed about their appearance, ${ }^{15}$ and suffer from functional, social, and occupational deficits. ${ }^{16,17}$ Psoriasis can seriously impair these patients' dating lives and relationships. ${ }^{18}$ Some $72 \%$ of psoriasis patients feel uncomfortable about dating and $60 \%$ report that this disease has prevented them from pursuing an intimate relationship. ${ }^{19}$ More than $80 \%$ of patients believe this disease to be misunderstood by the public, and $70 \%$ feel limited in their ability to function socially due to their psoriasis. ${ }^{19}$ Due to the sensitive location 
of genital psoriasis lesions, it is likely that this disease has great effects on quality of life, particularly in respect to sexual function.

Psoriasis is well-characterized to diminish quality of life on a variety of measures, but there is increasing interest in characterizing the quality of life impacts of psoriasis on patients with lesions within the genital area. This review evaluates the most current literature regarding the impact that genital psoriasis has on the quality of life of affected patients.

\section{Methods}

A literature search using the MEDLINE health literature database was conducted using the terms ("psoriasis") AND ("penile” OR "penis" OR "genital*” OR "glans" OR "scrotal” OR "scrotum" OR "anal” OR “diaper" OR "napkin" OR “shaft” OR “foreskin" OR “prepuce” OR "perianal” OR "vulva*” OR "labia” OR "labium" OR "groin” OR “preputial” OR “penoscrotal”) AND (“quality”). Two independent reviewers identified the included articles (EY and IS). Articles were included if they included patients with psoriasis affecting the genital area, discussed the quality of life effects or symptoms that these patients experienced due to their disease, and were published prior to April 8, 2018. Studies were excluded if they did not study genital psoriasis, did not discuss the quality of life effects of genital psoriasis, were of foreign language, were duplicates of already-included studies, or were reviews or meta-analyses. Study results were extracted using a standardized data form designed for this review topic.

\section{Quality of life instruments Dermatology Life Quality Index}

The Dermatology Life Quality Index (DLQI) is a 10-item questionnaire validated to evaluate quality of life impact and disability associated with skin disease. ${ }^{20}$ This questionnaire asks about the impact of skin disease on symptoms, selfperception, shopping, clothing choice, social activity, physical activity, working/studying, personal relationships, sexual functioning, and treatment. Patients indicate how much their skin disease affects their life for each topic, ranging from "not at all" to "very much". Each response is scored on a scale from 0 to 3 and summed to get a total score out of a maximum 30 points. A greater DLQI score indicates greater quality of life impairment.

\section{Female Sexual Distress Scale}

The Female Sexual Distress Scale (FSDS) is a 12-item questionnaire validated to evaluate sexually related personal distress in women. ${ }^{21}$ Patients indicate how often they are bothered by sexual problems, ranging from "never" to "always". Each response is scored on a scale from 0 to 4 and summed to get a total score out of a maximum 48. A greater FSDS score indicates greater sexual distress, with FSDS scores $\geq$ 15 indicating sexually related personal distress.

\section{Sexual Quality of Life Questionnaire for Use in Men}

The Sexual Quality of Life Questionnaire for Use in Men (SQoL-M) is an 11-item questionnaire validated to evaluate sexual quality of life in men with premature ejaculation or erectile dysfunction. ${ }^{22}$ Patients indicate their level of agreement with statements regarding thoughts and feelings about their sex life, ranging from "completely disagree" to "completely agree". Each response is scored on a scale from 1 to 6 , then summed, and scaled to a total score out of 100 . A greater SQoL-M indicates better sexual quality of life, with men reporting no problems with sexual function having an average SQoL-M score of $87 .^{22}$

\section{International Index of Erectile Function}

The International Index of Erectile Function (IIEF) is a 15-item questionnaire validated for the assessment of male sexual function within the domains of erectile function, orgasmic function, sexual desire, intercourse satisfaction, and overall satisfaction. ${ }^{23}$ Patients indicate the extent to which their sexual function is affected within each of these domains. Each response is scored on a scale from 0 to 5 and summed for a total score out of a maximum 75. An abridged 5-question version, the IIEF-5, can also be used to detect the presence of erectile dysfunction, with IIEF-5 score $\leq 21$ indicating erectile dysfunction. ${ }^{24}$ Lower scores on the IIEF indicate greater impairment of sexual function, whereas lower scores on the IIEF-5 indicate more severe erectile dysfunction.

\section{Dermatologic Intimacy Scale}

The Dermatologic Intimacy Scale (DIS) is an 18-item questionnaire used to evaluate the impact of skin disease on intimate relationships. ${ }^{18}$ This questionnaire asks patients about various aspects of intimacy, including relationships, comfort with nudity, emotions, and self-perception. Patients indicate the impact of their skin disease on intimacy, ranging from "not at all" to "very much". Each response is scored on a scale from 0 to 4 , then summed to get a total score out of a maximum 72. A greater DIS score indicates greater impairment in intimacy. 


\section{Results}

A total of 46 relevant citations were identified from our literature search (Figure 1). Of these, 23 articles were selected for further evaluation based on the relevance of their title and abstract. A total of 14 articles examining the quality of life effects of genital psoriasis were ultimately included in this study.

\section{Symptoms}

Genital itch was reported by $82 \%-100 \%$ of genital psoriasis patients and was the most commonly reported symptom found in our analysis (Table 1). ${ }^{6,25,26}$ Itching occurred at a greater intensity than burning or pain and was reported to be the most bothersome symptom in $40 \%$ of patients. ${ }^{25}$ Another $40 \%$ of patients were most bothered by stinging and burning in the

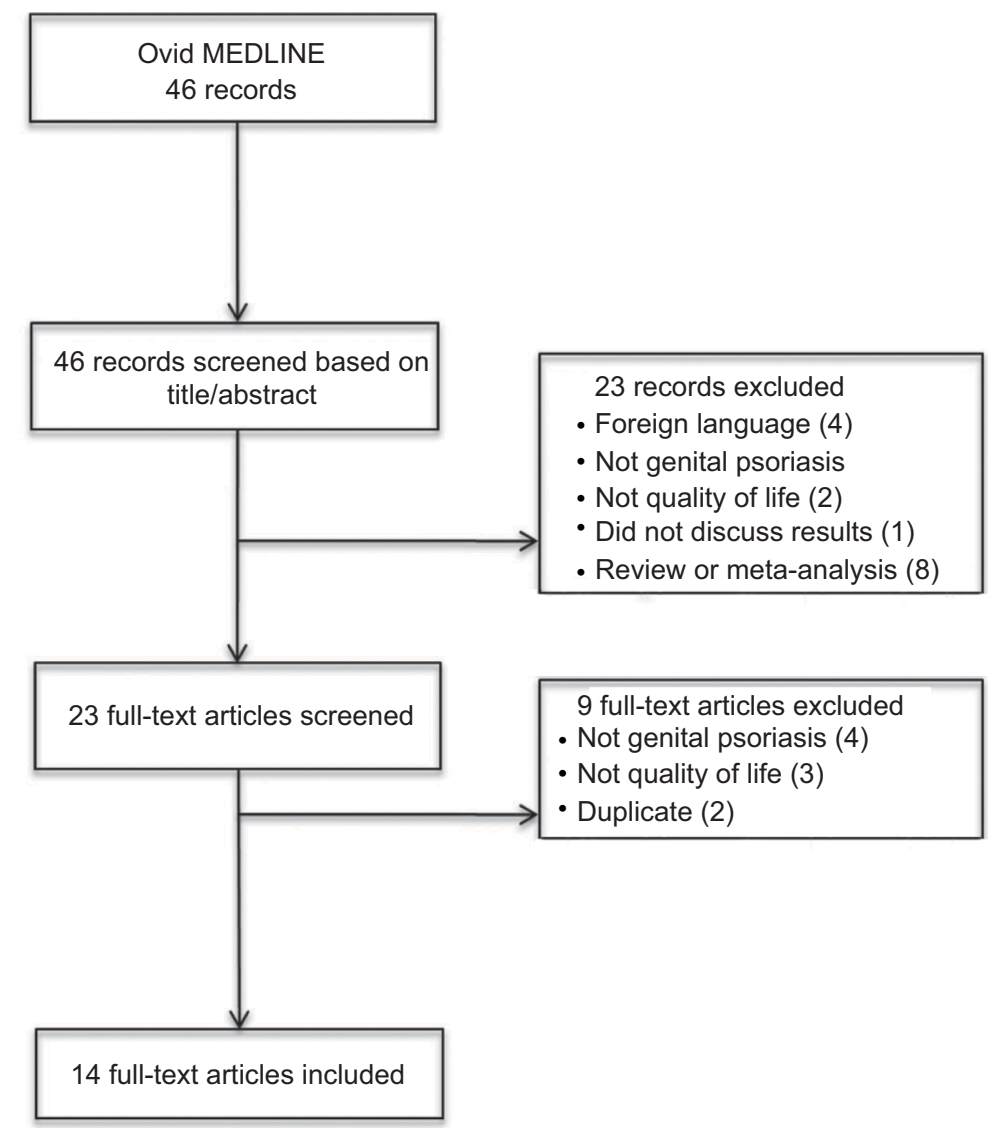

Figure I Study selection for quality of life effects of genital psoriasis.

Table I Studies evaluating the symptoms associated with genital psoriasis

\begin{tabular}{|c|c|c|}
\hline $\begin{array}{l}\text { Source } \\
\text { Author, year }\end{array}$ & Patients, $n$ & Symptoms \\
\hline Cather et al, $2017^{25}$ & 20 & $\begin{array}{l}\text { Genital itch }(100 \%) \text {, discomfort }(100 \%) \text {, redness }(95 \%) \text {, stinging/burning }(95 \%) \text {, pain }(85 \%) \text {, and scaling }(75 \%) \text {, } \\
\text { The most bothersome symptoms were reported to be itching ( } 40 \%) \text {, stinging/burning }(40 \%) \text {, and pain }(20 \%)\end{array}$ \\
\hline Meeuwis et al, $2012^{7}$ & 277 & $\begin{array}{l}\text { Patients endorse greater intensity of itch ( } 4.2) \text { compared with burning (3.5) and pain (2.8). Greater } \\
\text { intensity of redness ( } 5.1) \text { compared with scaliness ( } 3.7) \text { and induration (2.4). Intensity of all symptoms was } \\
\text { significantly higher for women compared with men. }\end{array}$ \\
\hline Ryan et al, $2015^{26}$ & 354 & $\begin{array}{l}\text { Genital itch }(86 \%) \text {, burning }(49 \%) \text {, pain }(44 \%) \text {. } \\
\text { Pain and burning reported significantly more frequently in females }\end{array}$ \\
\hline Zamirska et al, $2008^{6}$ & 22 & Itching/burning (82\%) \\
\hline
\end{tabular}


genital area, whereas the remaining $20 \%$ were most bothered by pain. Genital psoriasis lesions more characteristically presented with intense redness, with less scale or induration. ${ }^{7}$

\section{Effects on sexual function}

Patients with genital psoriasis experience significant impairments in sexual function compared with patients without genital involvement (Table 2). Patients with genital psoriasis experience decreased frequency of intercourse, avoid sexual relationships, and have reduced sexual desire. ${ }^{7,25-27}$ These patients are less comfortable with their own nudity, dating, and intimacy compared with patients with psoriasis lesions on nonsensitive areas of their body. ${ }^{18}$ Patients experience pain during intercourse or worsening of symptoms after intercourse as well. ${ }^{25}$ Women in particular experience dyspareunia and are distressed by the impact of genital psoriasis on sexual function compared with men. ${ }^{7,28}$ However, this distress improves with treatment targeted toward the genital lesions. ${ }^{28}$ Males also experience impairments in sexual function, ${ }^{7}$ but the presence of psoriasis lesions in the genital area was not associated with any statistical increase in erectile dysfunction. ${ }^{29,30}$

Table 2 Studies evaluating the effects of genital psoriasis on sexual quality of life

\begin{tabular}{|c|c|c|c|}
\hline $\begin{array}{l}\text { Source } \\
\text { Author, year }\end{array}$ & Patients, $\mathbf{n}$ & Scale & Effects to sexual quality of life \\
\hline $\begin{array}{l}\text { Bardazzi et al, } \\
2016^{30}\end{array}$ & NR & IIEF-5 & $\begin{array}{l}\text { No statistically significant difference in the rate of erectile dysfunction in psoriasis } \\
\text { patients with and without genital involvement, } 42 \% \text { of patients with ED also } \\
\text { had genital lesions. Seventy percent of patients with genital lesions did not feel } \\
\text { attractive, compared with } 60 \% \text { overall }\end{array}$ \\
\hline $\begin{array}{l}\text { Cabete et al, } \\
2014^{29}\end{array}$ & 36 & IIEF-5 & $\begin{array}{l}\text { Rate of erectile dysfunction was higher, but not statistically significant, in psoriasis } \\
\text { patients with genital involvement compared with patients without genital } \\
\text { involvement }\end{array}$ \\
\hline $\begin{array}{l}\text { Cather et al, } \\
2017^{25}\end{array}$ & 20 & $\begin{array}{l}\text { Patient interview } \\
\text { (Telephone) }\end{array}$ & $\begin{array}{l}\text { Impaired sexual experience during sexual activity }(80 \%) \text {, worsening of symptoms } \\
\text { after sexual activity }(80 \%) \text {, decreased frequency of sexual activity }(80 \%) \text {, avoidance } \\
\text { of sexual relationships ( } 75 \%) \text {, and reduced sexual desire }(55 \%) \text {. Impaired sexual } \\
\text { experience was due to both physical effects, such as cracking or pain, and } \\
\text { psychosocial effects, such as embarrassment and feelings of stigmatization. }\end{array}$ \\
\hline $\begin{array}{l}\text { Gupta et al, } \\
1997^{27}\end{array}$ & NR & $\begin{array}{l}\text { "Do you believe that since } \\
\text { the onset of psoriasis }\end{array}$ & $\begin{array}{l}\text { Greater psoriasis severity affecting the groin region was associated with a decline in } \\
\text { sexual activity }\end{array}$ \\
\hline
\end{tabular}

Gupta et al, NR "Do you believe that since your sexual activity has declined?"

Malakouti et al, $290 \quad$ DIS

$2017^{18}$

Meeuwis et al, $\quad 42$

$2015^{28}$

Meeuwis et al, $\quad 277$ $2011^{5}$

${ }^{5}$

\section{EQ-5D, EQ-VAS, DLQI, FSDS, SQoL-M} FSFI

Significantly greater intimacy impact than patients without genital involvement (DIS 34.7 vs 27.2)

Females had a mean FSDS 22.8, males had a mean SQoL-M 70.7. 8 of I 3 women

(62\%) had sexually related personal distress. Treatment with focus on genital lesions resulted in significant improvement in FSDS (8.I) by the next visit, no significant improvement in SQoL-M

DLQI, SQoL-M, FSDS, IIEF, Significantly more sexual impairment compared with patients without genital

involvement, no difference between males and females. No significant difference in SQoL-M or IIEF between men with and without genital involvement. Females with genital psoriasis had significantly greater sexual distress compared with patients without genital involvement (FSDS 16.I vs 10.1) and were more likely to be sexual distressed (50.8\% vs $32.1 \%$ ). No statistically significant difference in sexual function was found between women with genital psoriasis and those without Dyspareunia (45\%), worsening of genital psoriasis after intercourse (34\%), decreased frequency of intercourse due to genital involvement (46\%). Discomfort during intercourse reported significantly more frequently in females. Significantly impaired sexual function, decreased sexual frequency, increased fear of sexual relations compared with patients without genital involvement

\footnotetext{
Zamirska et al, $22 \quad$ BDI Patients with vulvar discomfort significantly more frequently stated that psoriasis had a negative influence on sex life $2008^{6}$

Abbreviations: NR, not reported; PISS, Psoriasis Internalized Stigma Scale; IIEF-5, International Index of Erectile Function-5; DIS, Dermatologic Intimacy Scale; FSDS, female sexual distress scale; SQoL-M, Sexual quality of life questionnaire for use in men; DLQI, Dermatological Life Quality Index; EQ-VAS, 5 dimension European QoL - visual analog scale; EQ-5D, 5 Dimension European QoL - index score; FSFI, Female Sexual Function Index; RLSS, Relationship and Sexuality Scale; QES, Questionnaire on Experience of Skin Complaints; BDI, Beck's Depression Index; CES-D, Center for Epidemiologic Studies Depression Scale.
} 


\section{Quality of life effects}

Patients with genital psoriasis demonstrate significantly diminished overall quality of life compared with psoriasis patients without genital involvement (Table 3). Patients with genital psoriasis experience impairments in physical activity, personal relationships, work and school, and emotions. ${ }^{25}$ Although these patients report stigmatization, two studies indicate that patients with genital involvement experience greater feelings of stigmatization than psoriasis patients without genital lesions, ${ }^{31,32}$ while one did not. ${ }^{33}$ Two other studies demonstrated that patients with genital psoriasis or genital discomfort experienced more depressive symptoms than patients without genital symptoms. ${ }^{6,26}$

\section{Discussion}

A number of studies have begun to characterize the quality of life impact of genital psoriasis, but these studies use various different quality of life instruments to capture this impact. Existing studies have found that genital psoriasis diminishes quality of life in various domains, particularly in respect to sexual function and distress (Table 2). Women in particular are distressed about genital lesions. Genital psoriasis patients experience frequent itching, burning, and stinging (Table 1), which can interfere with personal and sexual relationships. The quality of life impact of genital psoriasis is serious, and these patients are more depressed than their counterparts without genital involvement, who are already more depressed than the general healthy population (Table 3$) \cdot{ }^{13}$ However, more controlled studies are needed to better understand the full impact that genital psoriasis has on quality of life.

The use of varying quality of life instruments does not allow for comparison of these studies and may introduce a source of bias in existing analyzes. Patients are often reluctant to discuss genital issues with their physicians and may be too embarrassed to answer fully and completely about genital symptoms or sexual function in certain contexts. ${ }^{34}$ All 20 patients in the study by Cather et $\mathrm{al}^{25}$ preferred to be interviewed over the telephone rather than face-to-face, which the authors speculated to be possibly due to embarrassment or discomfort about discussing these sensitive topics. Thus, instruments not designed or validated to investigate quality of life impairments in this specific population of patients

Table 3 Studies evaluating the effects of genital psoriasis on overall quality of life

\begin{tabular}{|c|c|c|c|}
\hline $\begin{array}{l}\text { Source } \\
\text { Author, year }\end{array}$ & Patients, $n$ & Scale & Effects to overall quality of life \\
\hline $\begin{array}{l}\text { Alpsoy et al, } \\
2017^{31}\end{array}$ & 269 & PISS & $\begin{array}{l}\text { Significantly higher internalized stigma compared with those without genital } \\
\text { involvement (PISS } 64.0 \text { vs 59.2) }\end{array}$ \\
\hline $\begin{array}{l}\text { Cather et al, } \\
2017^{25}\end{array}$ & 20 & Patient interview (telephone) & $\begin{array}{l}\text { Impairments in mood/emotion (95\%), physical activities (60\%), relationships } \\
\text { with friends and family ( } 45 \%) \text {, and work/school (35\%) }\end{array}$ \\
\hline $\begin{array}{l}\text { Hawro et al, } \\
2017^{33}\end{array}$ & 29 & $\begin{array}{l}\text { Feelings of Stigmatization } \\
\text { Questionnaire }\end{array}$ & $\begin{array}{l}\text { No statistically significant difference in level of stigmatization in psoriasis } \\
\text { patients with and without genital involvement, all psoriasis patients reported } \\
\text { some level of stigmatization }\end{array}$ \\
\hline $\begin{array}{l}\text { Meeuwis et al, } \\
2015^{28}\end{array}$ & 42 & $\begin{array}{l}\text { EQ-5D, EQ-VAS, DLQI, FSDS, } \\
\text { SQoL-M }\end{array}$ & $\begin{array}{l}\text { Moderate adverse effect on patients' lives (DLQI 9.I), EQ-5D was similar } \\
\text { to general population, EQ-VAS was slightly lower than general population. } \\
\text { Treatment with focus on genital lesions resulted in significant improvement in } \\
\text { DLQI (4.I) and EQ-5D by the next visit (mean } 6 \text { weeks, range } 4-24 \text { weeks) }\end{array}$ \\
\hline $\begin{array}{l}\text { Meeuwis et al, } \\
201 I^{5}\end{array}$ & 277 & $\begin{array}{l}\text { DLQI, SQoL-M, FSDS, IIEF, } \\
\text { FSFI }\end{array}$ & $\begin{array}{l}\text { Significantly worse quality of life compared with patients without genital } \\
\text { involvement (DLQI } 8.5 \text { vs } 5.5 \text { ), significant with respect to personal relations, } \\
\text { symptoms and feelings, daily activities, leisure, work and school, and treatment. }\end{array}$ \\
\hline $\begin{array}{l}\text { Mercuri et al, } \\
2017^{43}\end{array}$ & 9 & PSOdisk & $\begin{array}{l}\text { Significantly worse quality of life than patients without genital involvement } \\
\text { (PSOdisk } 67.75 \text { vs } 47.5 \text { ) }\end{array}$ \\
\hline Ryan et al, $2015^{26}$ & 354 & RLSS, CES-D, DLQI & $\begin{array}{l}\text { Significantly greater quality of life impairment determined by DLQI ( } 8.7 \text { vs } 4.0) \\
\text { and CES-D (I3.8 vs II.0) than patients without genital involvement }\end{array}$ \\
\hline $\begin{array}{l}\text { Schmid-Ott et al, } \\
1999^{32}\end{array}$ & 51 & $\begin{array}{l}\text { Six-point Likert scale of } \\
\text { stigmatization experience, QES }\end{array}$ & $\begin{array}{l}\text { Significantly more patients felt stigmatized than patients without genital } \\
\text { involvement with respect to self-esteem, retreat, rejection, and concealment }\end{array}$ \\
\hline $\begin{array}{l}\text { Zamirska et al, } \\
2008^{6}\end{array}$ & 22 & $\mathrm{BDI}$ & $\begin{array}{l}\text { Patients with vulvar discomfort stated that itching/burning within vulva } \\
\text { had negative impact on psychosocial well-being ( } 64 \%) \text {. Patients with vulvar } \\
\text { discomfort had higher BDI ( } 9.6 \text { vs } 6.9) \text { and rates of depression ( } 39.0 \% \text { vs } \\
19.2 \%) \text { than patients without vulvar discomfort }\end{array}$ \\
\hline
\end{tabular}

Abbreviations: PISS, Psoriasis Internalized Stigma Scale; IIEF-5, International Index of Erectile Function-5; DIS, Dermatologic Intimacy Scale; FSDS, female sexual distress scale; SQoL-M, Sexual quality of life questionnaire for use in men; DLQI, Dermatological Life Quality Index; EQ-VAS, 5 dimension European QoL - visual analog scale; EQ-5D, 5 Dimension European QoL - index score; FSFI, Female Sexual Function Index; RLSS, Relationship and Sexuality Scale; QES, Questionnaire on Experience of Skin Complaints; BDI, Beck's Depression Index; CES-D, Center for Epidemiologic Studies Depression Scale. 
may be prone to misinterpretation and may not capture the true effects of genital psoriasis.

Validated instruments to measure quality of life in patients with scalp and nail psoriasis exist, ${ }^{35,36}$ but no such instruments have been validated yet for genital psoriasis. However, outcome measure scales are currently being developed to allow for better characterization of the quality of life impact that genital psoriasis has on patients' lives. ${ }^{37,38}$ These instruments may allow researchers and clinicians to better understand how different treatments impact quality of life in patients in clinical trials, an area where high-quality evidence is currently lacking. ${ }^{39}$ Genital psoriasis is uniquely challenging to treat because of the sensitivity and high absorption of topical agents in this area, ${ }^{40}$ so further studies using validated instruments are needed to assess the efficacy and safety of available therapies for genital psoriasis.

Affected body surface area has historically been used in the clinical setting to evaluate whether patients should be started on systemic treatment, but this paradigm has begun to fall out of favor. Localized psoriasis, such as involvement of the genitals, can significantly impair patients physically, socially, and emotionally, even to the point of debilitating depression. Patients with significant quality of life deficits due to skin disease are recommended to be started on systemic treatment, ${ }^{41,42}$ even without diffuse cutaneous involvement.

Unfortunately, genital psoriasis remains undertreated in the vast majority of patients. Up to two-thirds of genital psoriasis patients have never used treatment for their genital lesions, let alone systemic treatment, and almost half have never discussed the presence of genital lesions with their physician. ${ }^{7}$ Even up to $40 \%$ of patients with severe genital psoriasis lesions did not discuss these issues with their physician, indicating that feelings of stigmatization, shyness, or fear of judgment may prevent patients from inquiring about these problems during their healthcare visits. ${ }^{7}$ Only a quarter of genital psoriasis patients believe that their physicians paid enough attention to possible sexual problems, despite the evidence that all types of psoriasis affect sexual relationships and function. ${ }^{5,19}$

Because of the taboo nature of genital skin disease and sexual impairment, physicians should take a proactive approach and ask their psoriasis patients about symptoms involving the genital area. Quality of life impairment due to genital lesions can be improved with targeted treatment, so early detection of these effects may help prevent further functional and social deficits secondary to skin disease. ${ }^{28}$ The development of validated quality of life instruments for genital psoriasis is a step in the right direction toward helping clinicians to assess these impacts more easily and may help increase our understanding of the efficacy of various treatments for this difficult disease. ${ }^{38}$ Genital psoriasis is a burdensome skin condition that significantly diminishes psychosocial and sexual health, and increased awareness of this unmet need is needed to properly care for these patients.

\section{Disclosure}

WL was funded in part by grants from the National Institutes of Health (R01AR065174, U01 AI119125). JK is an advisor/ consultant/speaker for Abbott, Amgen, Astellas, Celgene, Janssen, Galderma, Eli-Lilly, Leo Pharma, Novartis, Pfizer/ Anacor, and Strata Skin Science. The authors report no other conflicts of interest in this work.

\section{References}

1. Parisi R, Symmons DP, Griffiths CE, Ashcroft DM, Identification and Management of Psoriasis and Associated ComorbidiTy (IMPACT) project team. Global epidemiology of psoriasis: a systematic review of incidence and prevalence. J Invest Dermatol. 2013;133(2):377-385.

2. Rachakonda TD, Schupp CW, Armstrong AW. Psoriasis prevalence among adults in the United States. J Am Acad Dermatol. 2014;70(3):512-516.

3. Farber EM, Nall ML. The natural history of psoriasis in 5,600 patients. Dermatologica. 1974;148(1):1-18.

4. Meeuwis KAP, Potts Bleakman A, van de Kerkhof PCM, et al. Prevalence of genital psoriasis in patients with psoriasis. J Dermatolog Treat. 2018:1-7.

5. Meeuwis KA, de Hullu JA, van de Nieuwenhof HP, et al. Quality of life and sexual health in patients with genital psoriasis. Br J Dermatol. 2011;164(6):1247-1255.

6. Zamirska A, Reich A, Berny-Moreno J, Salomon J, Szepietowski JC. Vulvar pruritus and burning sensation in women with psoriasis. Acta Derm Venereol. 2008;88(2):132-135.

7. Meeuwis KA, van de Kerkhof PC, Massuger LF, de Hullu JA, van Rossum MM. Patients' experience of psoriasis in the genital area. Dermatology. 2012;224(3):271-276.

8. American Academy of Dermatology Work Group, et al. Guidelines of care for the management of psoriasis and psoriatic arthritis: section 6 . Guidelines of care for the treatment of psoriasis and psoriatic arthritis: case-based presentations and evidence-based conclusions. $J$ Am Acad Dermatol. 2011;65(1):137-174.

9. Gelfand JM, Troxel AB, Lewis JD, et al. The risk of mortality in patients with psoriasis: results from a population-based study. Arch Dermatol. 2007;143(12):1493-1499.

10. Gelfand JM, Neimann AL, Shin DB, Wang X, Margolis DJ, Troxel AB. Risk of myocardial infarction in patients with psoriasis. JAMA. 2006;296(14):1735-1741.

11. Rapp SR, Feldman SR, Exum ML, Fleischer AB, Reboussin DM. Psoriasis causes as much disability as other major medical diseases. $J$ Am Acad Dermatol. 1999;41(3 Pt 1):401-407.

12. Gupta MA, Schork NJ, Gupta AK, Kirkby S, Ellis CN. Suicidal ideation in psoriasis. Int J Dermatol. 1993;32(3):188-190.

13. Kurd SK, Troxel AB, Crits-Christoph P, Gelfand JM. The risk of depression, anxiety, and suicidality in patients with psoriasis: a populationbased cohort study. Arch Dermatol. 2010;146(8):891-895.

14. Dowlatshahi EA, Wakkee M, Arends LR, Nijsten T. The prevalence and odds of depressive symptoms and clinical depression in psoriasis patients: a systematic review and meta-analysis. $J$ Invest Dermatol. 2014;134(6):1542-1551. 
15. Perrott SB, Murray AH, Lowe J, Mathieson CM. The psychosocial impact of psoriasis: physical severity, quality of life, and stigmatization. Physiol Behav. 2000;70(5):567-571.

16. Pearce DJ, Singh S, Balkrishnan R, Kulkarni A, Fleischer AB, Feldman SR. The negative impact of psoriasis on the workplace. J Dermatolog Treat. 2006;17(1):24-28.

17. Sampogna F, Tabolli S, Abeni D, IDI Multipurpose Psoriasis Research on Vital Experiences (IMPROVE) investigators. Living with psoriasis: prevalence of shame, anger, worry, and problems in daily activities and social life. Acta Derm Venereol. 2012;92(3):299-303.

18. Malakouti M, Brown GE, Leon A, et al. The dermatologic intimacy scale: quantitatively measuring the impact of skin disease on intimacy. J Dermatolog Treat. 2017;28(4):347-352.

19. Anstey A, McAteer H, Kamath N, Percival F. Extending psychosocial assessment of patients with psoriasis in the UK, using a self-rateds, web-based survey. Clin Exp Dermatol. 2012;37(7):735-740.

20. Finlay AY, Khan GK. Dermatology Life Quality Index (DLQI) - a simple practical measure for routine clinical use. Clin Exp Dermatol. 1994;19(3):210-216.

21. Derogatis LR, Rosen R, Leiblum S, Burnett A, Heiman J. The Female Sexual Distress Scale (FSDS): initial validation of a standardized scale for assessment of sexually related personal distress in women. $J$ Sex Marital Ther. 2002;28(4):317-330.

22. Abraham L, Symonds T, Morris MF. Psychometric validation of a sexual quality of life questionnaire for use in men with premature ejaculation or erectile dysfunction. J Sex Med. 2008;5(3):595-601.

23. Rosen RC, Riley A, Wagner G, Osterloh IH, Kirkpatrick J, Mishra A. The international index of erectile function (IIEF): a multidimensional scale for assessment of erectile dysfunction. Urology. 1997;49(6):822-830.

24. Rosen RC, Cappelleri JC, Smith MD, Lipsky J, Peña BM. Development and evaluation of an abridged, 5-item version of the International Index of Erectile Function (IIEF-5) as a diagnostic tool for erectile dysfunction. Int J Impot Res. 1999;11(6):319-326.

25. Cather JC, Ryan C, Meeuwis K, et al. Patients' perspectives on the impact of genital psoriasis: a qualitative study. Dermatol Ther. 2017;7(4):447-461.

26. Ryan C, Sadlier M, de Vol E, et al. Genital psoriasis is associated with significant impairment in quality of life and sexual functioning. $\mathrm{J} \mathrm{Am}$ Acad Dermatol. 2015;72(6):978-983.

27. Gupta MA, Gupta AK. Psoriasis and sex: a study of moderately to severely affected patients. Int J Dermatol. 1997;36(4):259-262.

28. Meeuwis KA, de Hullu JA, Inthout J, et al. Genital psoriasis awareness program: physical and psychological care for patients with genital psoriasis. Acta Derm Venereol. 2015;95(2):211-216.
29. Cabete J, Torres T, Vilarinho T, Ferreira A, Selores M. Erectile dysfunction in psoriasis patients. Eur J Dermatol. 2014;24(4):482-486.

30. Bardazzi F, Odorici G, Ferrara F, Magnano M, Balestri R, Patrizi A. Sex and the PASI: patients affected by a mild form of psoriasis are more predisposed to have a more severe form of erectile dysfunction. $J$ Eur Acad Dermatol Venereol. 2016;30(8):1342-1348.

31. Alpsoy E, Polat M, Fettahlioglu-Karaman B, et al. Internalized stigma in psoriasis: a multicenter study. J Dermatol. 2017;44(8):885-891.

32. Schmid-Ott G, Kuensebeck HW, Jaeger B, et al. Validity study for the stigmatization experience in atopic dermatitis and psoriatic patients. Acta Derm Venereol. 1999;79(6):443-447.

33. Hawro M, Maurer M, Weller K, et al. Lesions on the back of hands and female gender predispose to stigmatization in patients with psoriasis. $J$ Am Acad Dermatol. 2017;76(4):648-654.

34. Stead ML, Brown JM, Fallowfield L, Selby P. Lack of communication between healthcare professionals and women with ovarian cancer about sexual issues. Br J Cancer. 2003;88(5):666-671.

35. Ortonne JP, Baran R, Corvest M, Schmitt C, Voisard JJ, Taieb C. Development and validation of nail psoriasis quality of life scale (NPQ10). $J$ Eur Acad Dermatol Venereol. 2010;24(1):22-27.

36. Chen SC, Yeung J, Chren MM. Scalpdex: a quality-of-life instrument for scalp dermatitis. Arch Dermatol. 2002;138(6):803-807.

37. Gottlieb AB, Kirby B, Ryan C, et al. The development of a patientreported outcome measure for assessment of genital psoriasis symptoms: The Genital Psoriasis Symptoms Scale (GPSS). Dermatol Ther. 2018;8(1):45-56.

38. Gottlieb AB, Kirby B, Ryan C, et al. The development of the Genital Psoriasis Sexual Frequency Questionnaire (GenPs-SFQ) to assess the impact of genital psoriasis on sexual health. Dermatol Ther. 2018;8(1):33-44.

39. Meeuwis KA, de Hullu JA, Massuger LF, van de Kerkhof PC, van Rossum MM. Genital psoriasis: a systematic literature review on this hidden skin disease. Acta Derm Venereol. 2011;91(1):5-11.

40. Farage M, Maibach HI. The vulvar epithelium differs from the skin: implications for cutaneous testing to address topical vulvar exposures. Contact Dermatitis. 2004;51(4):201-209.

41. Callen JP, Krueger GG, Lebwohl M, et al. AAD consensus statement on psoriasis therapies. J Am Acad Dermatol. 2003;49(5):897-899.

42. Feldman SR, Koo JY, Menter A, Bagel J. Decision points for the initiation of systemic treatment for psoriasis. J Am Acad Dermatol. 2005;53(1):101-107.

43. Mercuri SR, Gregorio G, Brianti P. Quality of life of psoriasis patients measured by the PSOdisk: a new visual method for assessing the impact of the disease. G Ital Dermatol Venereol. 2017;152(5):424-431.
Psoriasis: Targets and Therapy

\section{Publish your work in this journal}

Psoriasis: Targets and Therapy is international, peer-reviewed, open access journal focusing on psoriasis, nail psoriasis, psoriatic arthritis and related conditions, identification of therapeutic targets and the optimal use of integrated treatment interventions to achieve improved outcomes

\section{Dovepress}

and quality of life. Visit http://www.dovepress.com/testimonials.php to read real quotes from published authors. 